\title{
Research on the Development and Practice of School- enterprise Integration Teaching Information Course on the Basis of "STC+ four-in-one"
}

\author{
zhimin $\mathrm{Yu}$ \\ Tianjin Maritime college \\ Tianjin, 300350, China
}

\begin{abstract}
The purpose of this paper is to reforming curriculum by integrating characteristics of education informatization in China with the up to date STC concept of American vocational education. This paper provides that curriculum design is modular, curriculum implementation is teamed, curriculum evaluation is diversified, and the curriculum application is lifelong. So in this paper, the curriculum design is modularized, the knowledge point is "fragmented", curriculum is implemented in a team, and the composition of the teacher team including industry experts, corporate tutors and full-time teachers, reflects the integration of school and enterprise. Finally, this paper suggest to deepen the integration of school-enterprise and research-assisted curriculum, release the role of information technology in the reform and development of education and teaching, ensure the vitality of education informationization, organically combine information technology and teaching and management so that the education informationization accelerates the construction of "learners" Centered teaching course. In addition, this paper firstly put forward the "STC+four integration" education informationization course construction concept.
\end{abstract}

Keywords-STC; Course development; Teaching practice; Information course

\section{INTRODUCTION}

The degree of informatization of the society is deepening, and the influence of information technology on higher vocational education is becoming more and more obvious. The informationization of higher vocational education is welcoming a major historical development opportunity. In 2010, the Central Committee of the Communist Party of China and the State Council issued the "Outline of Talent Planning" to propose "Information Technology for Education". Development has revolutionary impact. In 2011, the Ministry of Education reorganized the informationization leading group In 2012, the Ministry of Education issued the 10-year development plan for education informatization, which proposed "innovation of education through education informatization". In 2014, the State Council accelerated the development of modern vocational education.[2] "Decision" clearly states that "deepening the integration of production and education, encouraging industries and enterprises to organize or participate in the organization of vocational education." Integration of production and education, integrated education is an effective way to train high-quality skilled personnel in vocational schools. In 2015, President Congratulatory letter of the first International Education Informatization Conference "actively promote the integration of information technology and education, innovation and development",[1]"perseverely promote education informationization, and strive to expand the coverage of quality education resources by means of informationization." During the "13th Five-Year Plan" period, the overall improvement Promote the quality of education and promote educational equity at a higher level Important tasks such as accelerating the process of education modernization have put forward higher requirements for education informationization, and provided a broader space for the development of higher vocational education informationization. At the end of 2017, the State Council issued a number of "Opinions on Deepening the Integration of Production and Education" Put forward "common education, cooperative research, joint construction of institutions, and sharing of resources". In 2018, the "Professional Schools and Enterprises Cooperation Promotion Measures" was formulated and 56 industry steering committees were reorganized and adjusted to improve the national vocational education standards system. The STC concept is the current US [3]. The reform and practice of vocational education is the concept of "from school to career". It is a lifelong vocational education concept that emphasizes the development of everyone and pays attention to the development of students' subjectivity. The core connotation is the field of vocational education theory and practice, and the STC concept dominates the United States. The development direction of vocational education in the new century. The curriculum of "five integration" is the modularization of curriculum design,[4] the teamization of curriculum implementation, the diversity of curriculum evaluation, and the lifelong application of curriculum. The core idea of the curriculum is "student as the main body", Everything for each student's career development." 


\section{SOLVE PROBLEMS AND SOLUTIONS}

\section{A. Solve problems and solutions}

Solve the problem of "two layers of skin" in teaching informationization and traditional courses, and realize curriculum development and application.Based on the superstar network platform, the construction of the course includes course introduction, teaching methods and teaching methods, teaching effects, reference materials, teaching resources, and course chapters. Teachers can use the Superstar network platform for long-term curriculum loop construction. The core idea of the new curriculum concept is "everything for each student's development." At present, the differentiation and individualization of higher vocational students are prominent. The design of teaching content should be gradual, and the task should be used to set the content. The tasks include basic tasks, discussion tasks, and expansion tasks. In the basic task setting, the principle is to take care of the characteristics of different students. The principle of demand, is gradual, from the table to the inside, from the shallow to the deep, while considering the size of the task, the decomposition of large tasks, the difficulty of knowledge points, the fusion of knowledge points and so on. The discussion task should pay attention to the students to leave a certain space for exploration and self-exploitation, cultivate students' innovative ability, skill and technical literacy training, discuss the task of on-the-job experts, including graduate students, to improve the pertinence and timeliness of the discussion. The main purpose of the expansion task is to understand the latest developments in the industry, the latest developments in the industry, the direction of industry development, the ability to cultivate independent learning, and the accumulation of social experience. The Panya network teaching integrated service platform is to use the network to expand the traditional teaching mode, which can better carry out knowledge learning and enhance personal literacy and self-learning ability. Course construction [5]. The final ship master and shafting installation course teaching process. Course basic information maintenance, interactive activity organization, learning effect evaluation and evaluation and course organization and management, course construction final ship host and shafting installation courses can be pure network, mixed mode, network-assisted multiple teaching modes. Students in school and after graduation can use the platform to $\log$ in to the course website to conduct basic activities such as basic tasks, discussion tasks, expansion tasks, and topic discussions. You can view the application materials based on the superstar network platform ship mainframe and shafting installation course. The teaching resources are updated daily, enter the learning community to share and exchange, and break the time and space constraints.

The superstar network course is combined with the traditional course. Through the combination of the class and the class, the student is the main body and the teacher is the leading mode. According to the course, the activity library of the mobile phone version is used flexibly. Activities can include check-ins, questionnaires, voting, questioning, temporary assignments, course evaluations, discussions, online classes, and live courses. Using the activity library to assist teaching, you can post a check-in 3 minutes before class to understand the student's attendance. There are many modes for sign-in. For example, a regular check-in can ask students to upload a selfie or not. The new class is recommended to use the self-portrait photo mode for the first time.[6] Check in to help teachers understand the situation of students. In addition, you can also use the gesture check-in, similar to the phone to lock the screen and enter the required gestures before you can use the phone. The gesture teacher can be arbitrarily set, and then the student is told to sign in, and the sign-in can also be checked in by using the location check-in and the twodimensional code. After class, the students open the course chapter, and the teaching implementation chapter process is shown in Figure 1-3. The content of the course chapter is similar to the traditional ppt function. It checks the tasks of the students under the class, asks questions through the "selection" mode, adds points according to the answer to the questions, and adopts the "answer" mode for simple questions. Set the first 5 points, the second to the fifth, and the teacher in the classroom to control the time is generally completed within 5-10 hours, and then focus on the difficult points of the task and the high error rate of the class. The use of a live broadcast mode for knowledge and professionalism allows students to review and train the overall quality of students. Industry experts and outstanding graduates are regularly invited to interact with students to consolidate and improve students' knowledge and skills. Gradually complete the teaching tasks according to the tasks in the course construction. Near the class, students will take 1-5 minutes to conduct selfevaluation, student mutual evaluation, evaluation of course content and evaluation of teachers, and complete course teaching.

\section{B. Solve the problem of insufficient analysis of the academic situation, analyze the chemical situation, teach students in accordance with their aptitude}

The course "study analysis" for the smooth implementation of the teaching objectives, the analysis of the situation is the main part of the teaching, as long as you understand and familiar with the students' participation in the course of knowledge, the knowledge of the "postentertainment" It is only necessary to supervise and promote learning. Teachers analyze students' various situations and guide students to complete various learning activities so as to achieve targeted goals. Superstar learning statistics, including task point monitoring, chapter learning visit statistics, chapter test statistics, student management, grade management, supervision, subject activities, and course credit statistics. For students' enthusiasm for the course, students can access the course statistics. According to statistics, in January 2018, $93.69 \%$ of the students in the $15-3$ class of the ship learned the course through mobile phones, and $6.31 \%$ of the students used the computer to study the course, indicating that the frequency of students using the smart phone is much higher than that of using the computer.Students use the learning pass to perform the frequency statistics for January, as shown in Figure 1. 


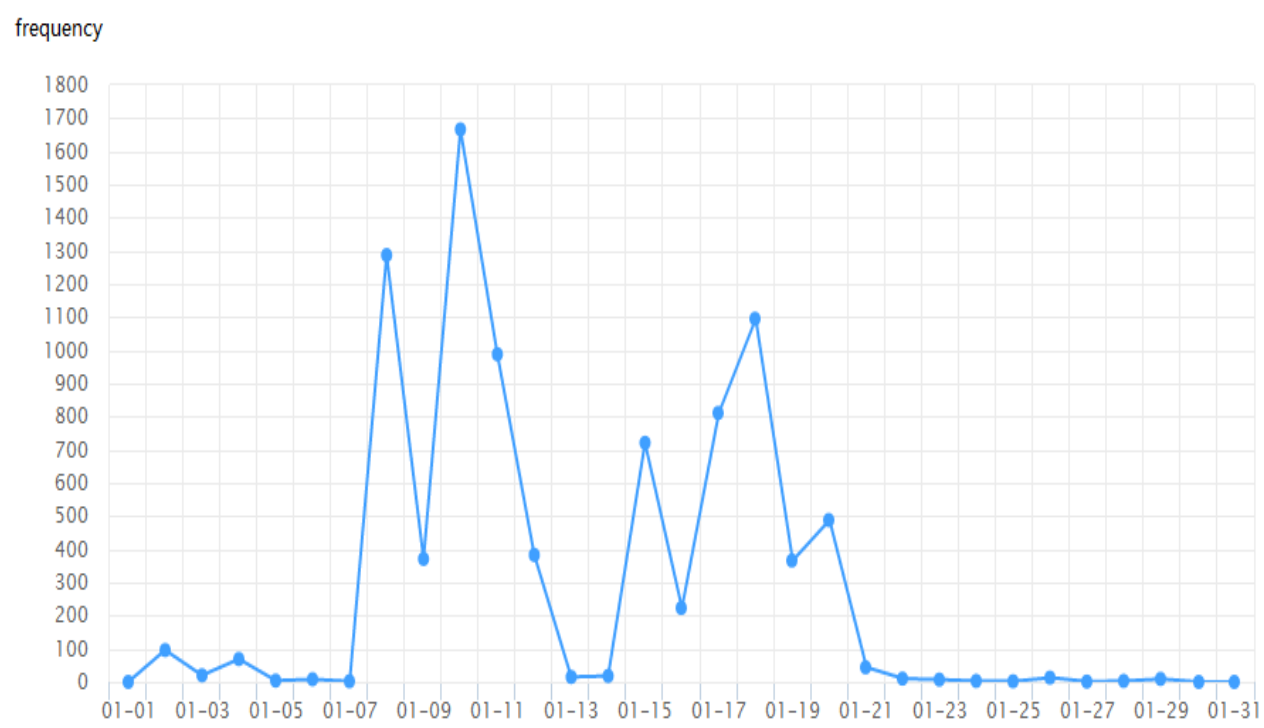

Fig. 1 Learning pass for January frequency statistics

On January 9th, January 10th, and January 18th, 2018, the number of student visits soared. Looking at the teacher's class schedule, it was found that the course students of the class took classes in these days, while the other time visits the difference. Very large, indicating that the enthusiasm of students to learn independently should be improved, and students' initiative in curriculum learning should be strengthened. In particular, on January 10th, there were exchanges and interactions among outstanding graduates of our school, indicating that students' attention and enthusiasm for future work are very high.The student task assignment and score analysis, as shown in Figure 2,

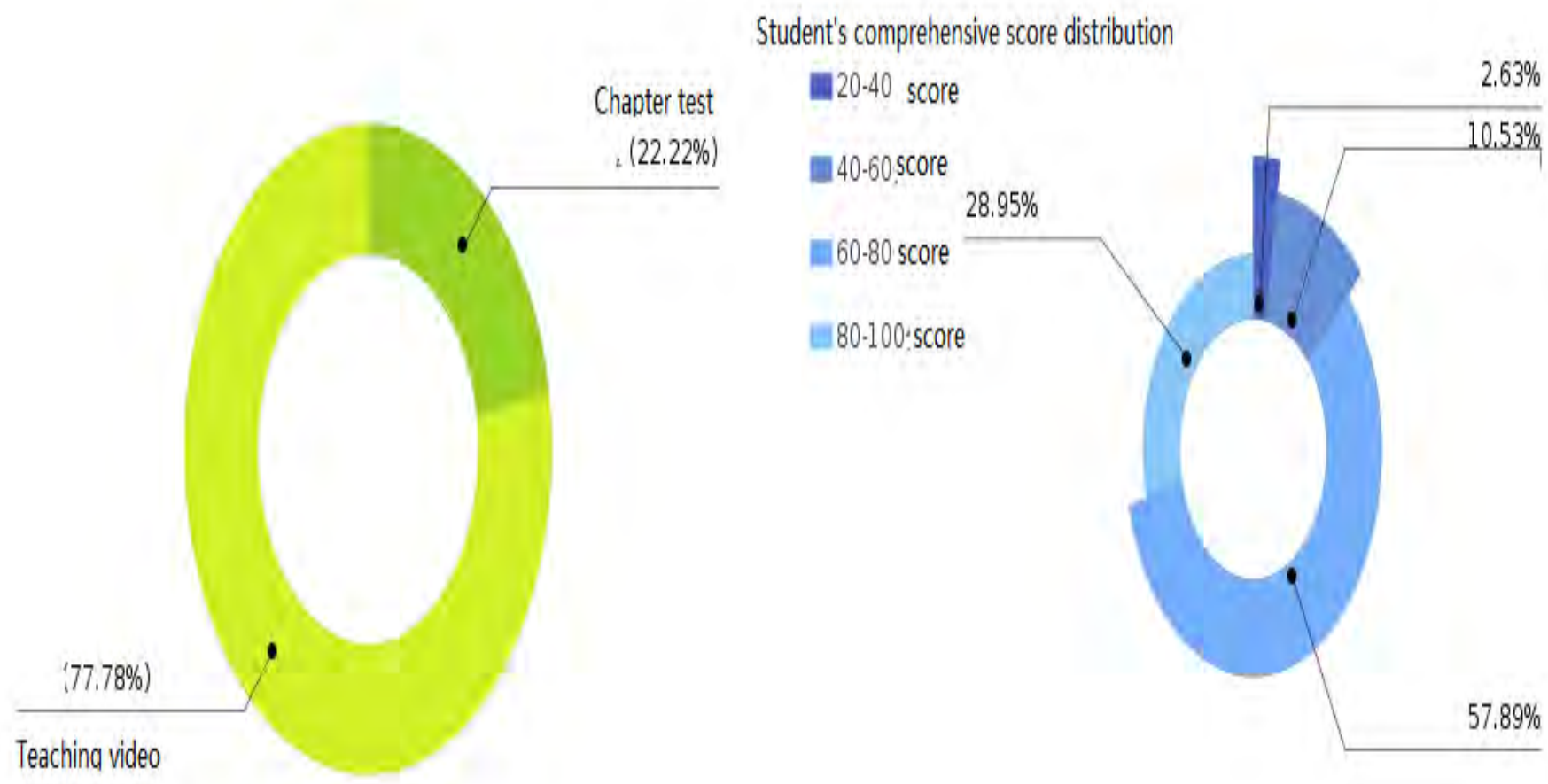

Fig. 2 Student course assignment, score analysis chart

the video task in the picture accounted for $77.78 \%$, the video task accounted for $77.78 \%$ of the total task, the student completed the video task is as shown in the figure, students can complete the task according to the requirements, some students feedback More than 300\%, indicating that the students' enthusiasm for learning is very high, the same task video is viewed more than 3 times, and the chapter test tasks account for $22.22 \%$ of the total tasks, but the completion is far 
from ideal for video tasks. Explain that students are interested in 5-10 minutes of video than traditional text exercises. In order to avoid boring text exercises, students are not interested, adopt interactive ideas, edit videos, play video exercises for 23 minutes, and complete chapter exercises. After that, you can learn the following video tasks, and use the interactive mode of video and practice to improve the knowledge of the students. The student's grades basically satisfy the normal distribution, and are not ideal for some students. They should be strengthened and urged to give more attention, love and help.

\section{Solve the problem of curriculum development from practical production, school-enterprise integration, research-assisted curriculum development and application}

In the course of curriculum development, I received support from the ship's marketing committee. I have researched the industry and enterprises for many times, realized the development of school-enterprise integration courses, and used the subject-assisted curriculum development to complete the research topic of the tooling based on the ship's mainframe and shafting installation tools, and applied for a patent. It is a teaching tool for simulating the research and development of marine diesel engine moving blocks. It is recognized by the research industry of the project and won the second prize of the teaching results awarded by the 2017 Marine Technical Committee. It won the first prize of the 2017 Excellent Technical Paper of the Ship Technology Committee. Fully communicate with industry experts and participate in the 2017 China Navigation Academic Annual Meeting and the 2017 Asian Navigation Academic Annual Meeting.

\section{RESULTS PROMOTION AND EFFECTIVENESS}

The research results guide the construction of the training room, and provide technical guidance and installation and debugging suggestions during the construction. Support $\mathrm{Wu}$ Chuntao, the shafting installation instructor of Yan'an Vocational and Technical College in the revolutionary old district to conduct guidance, communication and exchange. The Yangtze River Shipbuilding Group recruits students from the shafting competition and conducts key training.

The courses are applied in the teaching of the 15th, 16th and 17th grade students of the school, the teaching of the national ship mainframe and the shafting competition. In 2015, our students won the group in the national host and shafting installation competition. prize. The educational informatization course should reflect the "three-use", that is, the use of the class, the use of the class, and the time-use. In the excellent teaching of the network teaching platform of the Tianjin Maritime Vocational College, the superstar user level "5 full class" used 151,361 times, note 543, Focus on 541, study 428, reading for more than 35 hours.

The content of the course should keep pace with the times. With the development of science and technology, the teaching content will be updated. The updated basis is based on industry standards, the latest development needs of the industry, the latest achievements of the industry, etc, the 15th, 16 th and 17 th students of the ship, teaching In the application, the student evaluation is good. The school-integrated teaching information construction and practice adapt to the development of the times, and promote the construction of "ship diesel engine", "ship security awareness and responsibility", "ship arming and management" and other courses in the school, and regularly communicate with enterprises and industries. Get the participation, recognition and praise of enterprises and industries. With the development of the times, the criteria for evaluating teachers should not be limited to teachers' "teaching well". They should also be evaluated from the perspective of students' "learning well". Students learn through the curriculum to achieve "soft goals", namely, professional ethics, craftsmanship, Innovative spirit, to achieve "hard targets" that is professional knowledge, professional skills, professional capabilities. The content of the course should keep pace with the times. With the development of science and technology, the teaching content will be updated. The updated basis is based on industry standards, the latest development needs of the industry, the latest achievements of the industry, etc. Through the interactive evaluation system, with the help of students and employees (Or graduate students), experts and other multievaluation courses, according to the evaluation feedback to improve the content of the course, this aspect alone can not be completed by the ability of teachers, it is recommended that the state to carry out policy support and college financial support, enterprise joint promotion to create can achieve lifelong The core curriculum of vocational learning.

\section{CONCLUSIONS AND INNOVATIONS}

For the first time, put forward the concept of "STC + five integration" education informationization course construction. The characteristics of China's education informatization are integrated with the latest STC concept in the United States. Based on the concept of "STC+Four Integration". superstar network course construction, realize "four integration", namely, curriculum design modularization, curriculum implementation teamwork, curriculum Assessment of diversity, lifelong application of curriculum. Course design utilizes knowledge points "fragmentation", modularization, and curriculum implementation teamwork. The composition of the teacher team reflects the characteristics of schoolenterprise integration, with industry experts, corporate tutors, and full-time teachers. Course assessment is diversified, student mutual evaluation, teacher evaluation, corporate tutor evaluation, and industry expert evaluation. The application of the course is lifelong, the content of the course is advancing with the times, and "updated from time to time" to meet the requirements of industry and enterprise development.

Network technology changes students' learning styles, learns time and space, masters more skills and knowledge in a short time, and can consult industry experts to improve learning efficiency through the network. Lifelong professional learning for the 21 st century is a guarantee for cultivating ingenuity. Through the establishment and use of online courses, students' lifelong learning, life and career development after school graduation are subject to the attention of the college and teachers. Graduates can guide the students' learning, which is the spiritual support and strength 
pillar of the students. Through the construction of ship security awareness and responsibility curriculum, teaching implementation, academic analysis, evaluation feedback, curriculum improvement and other aspects, it is feasible to verify the Internet + lifelong education model. The combination of the Internet and traditional courses is more conducive to improving students' enthusiasm. Conducive to the overall development of students.

The "five-in-one" curriculum is structured with modular curriculum design, curriculum implementation teamwork, curriculum evaluation diversification, and curriculum application lifelong. The core idea of the curriculum is "student-centered" and "all for each student's career." development of".The "five-in-one" curriculum is structured with modular curriculum design, curriculum implementation teamwork, curriculum evaluation diversification, and curriculum application lifelong. The core idea of the curriculum is "student-centered" and "all for each student's career." development of".The "five-in-one" curriculum is structured with modular curriculum design, curriculum implementation teamwork, curriculum evaluation diversification, and curriculum application lifelong. The core idea of the curriculum is "student-centered" and "all for each student's career.

\section{ACKNOWLEDGMENT}

This paper is the research result of the teaching reform of the "Thirteenth Five-Year" Tianjin Higher Vocational Education Teaching Reform Project "Based on Internet + Ship Security Awareness and Responsibility Course MultiInteraction Evaluation Research", project approval number 201854.

\section{REFERENCES}

[1] Kai Zhao. The Revelation from Sun Shaoping's Career Developmen Course in Novel Ordinary World for Contemporary College Students[A] Wuhan Zhicheng Times Cultural Development Co., Ltd. Proceedings of 2nd International Conference on Economics and Management Education, Humanities and Social Sciences(EMEHSS 2018)[C]. Wuhan Zhicheng Times Cultural Development Co., Ltd.

[2] Fangfang Ma. Educational Reform of Public Psychology Course in Normal Colleges and Universities under the Background of Transition Development[A]. Information Engineering Research Institute, USA, Singapore Management and Sports Science Institute, Singapore. Proceedings of 2018 3rd PIL International Conference on Business, Social Sciences and Information Science (PIL-BSI 2018)[C].Information Engineering Research Institute, USA, Singapore Management and Sports Science Institute, Singapore.

[3] Zhengyu Fan. Teaching Practice Research of Webpage Design and Making Course--Development of Mental Health Education Websites Based on Project Teaching[A]. Information Engineering Research Institute, USA, Singapore Management and Sports Science Institute, Singapore. Proceedings of 2018 5th ERMI International Conference on Social Issues, Social Work and Social Sciences (ERMI-SSS 2018) [C] Information Engineering Research Institute, USA, Singapore Management and Sports Science Institute, Singapore.

[4] Yanzizhe. Research on the development course of Internet finance and its impact on the earnings of commercial banks [A]. Proceedings of 2017 World Symposium on Economics, Business and Management (WSEBM 2017).

[5] Chao Yang. Continuing education curriculum construction for primary and secondary school teachers based on education informatization[A] American Applied Sciences Research Institute, AASRI; American Applied Sciences Research Institute, AASRI. Proceedings of the 2014 International Conference on Sport Science and Computer Science(SSCS 2014) \& The 2014 International Conference on Biomechanics and Sports Engineering(BSE 2014)[C].American Applied Sciences Research Institute, AASRI; American Applied Sciences Research Institute, AASRI. 